\title{
POLICYMAKING ON WATERSIDE INDUSTRIAL SITES: AN EMPIRICAL STUDY FOR FLANDERS
}

\author{
Tom Pauwels \\ Eddy Van de Voorde \\ Thierry Vanelslander \\ Ann Verhetsel \\ Department of Transport and Regional Economics - University of Antwerp \\ Prinsstraat 13 \\ B-2000 Antwerpen \\ Belgium \\ Tel. -32-3 2654180 \\ Fax -32-3 2654395 \\ \{tom.pauwels ; eddy.vandevoorde ; thierry.vanelslander; ann.verhetsel\}@ua.ac.be
}

\begin{abstract}
A pertinent question in a country confronted with high demand from various sources for scarcely available land is how to generate the highest social value from existing space. In such a setting, moreover, growing environmental awareness and economic efficiency make inland navigation an attractive option. This will inevitably translate into a greater need for waterside industrial sites (i.e. sites with cargo transfer via inland waterways). The present research paper proposes a methodology whereby government can prioritize investment decisions in additional waterside land and applies the approach to the situation in Flanders. Public policy is, after all, concerned with providing sufficient space for economic activities while ensuring optimal spatial and functional allocation and taking adequate account of future trends and developments. A number of scenarios are proposed along which the future inland navigation market may evolve given a number of policy assumptions. The Freight Model Flanders allows one to simulate future freight flows by mode (i.e. road, rail and inland waterways) and freight category. When combined with a survey-based quantitative analysis, it is possible to arrive at a prioritization between regions in respect of additional investment in the availability of waterside land. This paper discusses with the quantitative aspects of a study entitled "Policy for the supply of waterside industrial sites and waterside transshipment locations", which was carried out at the request of the Flemish Government.
\end{abstract}

Keywords: Inland navigation, waterside industrial sites, transport policy, spatial planning, Flanders, land-use

$12^{\text {th }}$ WCTR, July 11-15, $2010-$ Lisbon, Portugal 


\section{RATIONALE AND SETTING}

Given the scarcity of land and expected growth in inland navigation1, it is important that government should be able to accurately estimate future demand for waterside industrial sites (i.e. sites with cargo transfer via inland waterways). Some of the forecast growth in inland navigation can be accommodated by existing areas, but a need for additional land is certain to arise. For allocation purposes, it is also important that a priority list of possible locations be drawn up.

Without policy action, companies at waterside locations may, in the long run, expect to face spatial issues. Therefore, it is necessary that government should adopt a proactive attitude and create a land stock that is managed rationally.

At the request of the Flemish Government's Agency for the Economy (Agentschap Economie), Arcadis and the University of Antwerp (Department of Transport and Regional Economics) are conducting a study into policymaking on the supply of waterside industrial land and water-based transshipment locations. Part of the study aims at a quantitative and qualitative assessment, on the basis of the most likely scenarios, of future developments in industrial and transshipment activity along Flanders' navigable waterways (horizon: 2020). In the present paper, the focus is on the quantitative analysis, which was performed by the University of Antwerp.

In stark contrast with the importance of the issue at hand is the absence of a referential framework for assessing which investment opportunities will generate the highest social value. Hence, a methodology for determining the base stock of waterside industrial land is urgently needed.

\section{RESEARCH QUESTION AND METHODOLOGY}

Research questions relevant to the study are:

a. What is the pattern of water-related land-use in Flanders? Which stakeholders are involved? What are the policy and societal developments?

b. What are the critical success factors and which elements are crucial for matching the demand for and supply of waterside industrial land?

c. Can we develop indicative scenarios for future evolutions in the inland navigation market?

d. How can we select priority regions for investment in waterside industrial land on the basis of a quantitative analysis?

In this paper, we focus on the latter two research questions in particular. For details regarding the other questions, see the report previously delivered to Agency for the Economy (Arcadis and University of Antwerp, 2008a).

\footnotetext{
${ }^{1}$ Inland navigation in this study refers to the use of up to 12000 metric tonne vessels in Flanders (Belgium).
}

$$
12^{\text {th }} \text { WCTR, July 11-15, } 2010-\text { Lisbon, Portugal }
$$


In Arcadis and University of Antwerp (2008a), an analysis is made of water-related land-use in Flanders, its suppliers and users, and relevant policy and societal developments. Micro as well as macro trends are taken into account. A geographic overview is provided of existing waterside industrial sites and availability bottlenecks. The various players in the transport chain, and particularly in inland navigation, are analysed. Implemented or planned policy actions are assessed. A SWOT analysis is made of the current market for waterside industrial land. The resulting strengths, weaknesses, opportunities and threats provide insight into the success rate of policy actions with respect to waterside industrial sites, leading to the identification of critical success factors, with a view to assisting government in outlining an optimal reservation and allocation policy.

The quantitative analysis presented in this paper proceeded along the following steps:

- Simulation of inland navigation flows on the basis of scenarios;

- Survey-based determination of regional demand for waterside industrial sites;

- Prioritisation of regions for further investment in the availability of such sites.

The methodology applied is demand-oriented. The analysis starts from current, existing demand and assumptions regarding its future evolution. The horizon is the year 2020 and the analysis is carried out at the Flemish NUTS-3 level (arrondissementen, or districts).

\section{DETERMINING FUTURE DEMAND FOR INLAND NAVIGATION}

At the request of the public authorities (Kenniscentrum Verkeer en Vervoer, afdeling Verkeerscentrum), a new Freight Model Flanders has been developed by K+P Transport Consultants, Tritel and Mint.

On the basis of this freight model, it is possible to simulate future freight flows by mode (road, rail and inland waterways) and NST freight category. A classic 4-step model is applied:

- Flow generation: in this step, we determine the flows arriving in or departing from a particular zone within a particular timeframe. In the case of freight transport, this means that, for a given freight category $k$, we calculate the tonnage departing from (or arriving in) zone $i(j)$ within a given period;

- Distribution of flows: the generation of flows serves as an input for this subsequent step. Now, the freight flows are determined between zones $i$ and $j$;

- Modal choice: here we determine which mode is used to transport tonnages from zone $i$ to $j$;

- Assignment: this step relates to route choice (after translation of tonnages into number of vehicles by means of a traffic conversion model).

Transport Logistic Nodes (distribution center for road transport) and inland terminals (for inland navigation) are also included in the model.

$12^{\text {th }}$ WCTR, July 11-15, $2010-$ Lisbon, Portugal 
The Freight Model Flanders is used to determine the impact of hypothetical scenarios on future freight transport.

It is important to note that, in the freight model, ongoing infrastructure projects ("lopende programma") by the Flemish government are taken into account. More specifically, the following infrastructure works are assumed to have been implemented by 2020 :

- the Oosterweel connection ${ }^{2}$;

- AX connection between N49 and N31;

- Liefkenshoek rail tunnel;

- Seine-Scheldt connection;

- Albert canal capacity increase.

The model is currently being analyzed in cooperation with the "Steunpunt Goederenstromen" (validation and sensitivity analysis). A comparison is being made with traffic counts and the evolution of modal shares according to MIRA-T 2007. Preliminary results point at a good match and are considered as a first indication of reliability (Borremans et al., 2008).

\subsection{Scenario building}

Each scenario is a combination of three types of assumptions: economic assumptions, policy assumptions and assumptions for inland navigation. In this paper, we focus on the principal assumptions only.

\subsubsection{Economic assumptions}

Economic growth will lead to an increase in transport (cf. the principle of derived demand). Hence, different assumptions regarding the rate of economic growth shall yield different outcomes in terms of freight transport and inland navigation in particular.

In European Energy and Transport Trends to 2030 - update 2005 (European Commission, 2006), an annual economic growth of $2 \%$ up to 2020 is forecast for Belgium. This economic growth represents the yearly evolution of the Gross Domestic Product (GDP) in real terms (adjusted for inflation), giving rise to three economic assumptions in the present research project:

- Economic assumption 1, "low growth": growth GDP $-0.5 \%=1.5 \%$

- Economic assumption 2, "normal growth": growth GDP $=2 \%$

- Economic assumption 3, "high growth": growth GDP + 0.5\% $=2.5 \%$

Insofar as the model requires input in relation to foreign zones, the actual evolution of GDP is used. We also refer in this respect to European Commission (2006).

\footnotetext{
${ }^{2}$ It is assumed that, with the completion of the Antwerp ring road, road freight shall no longer be allowed to pass through the Kennedy Tunnel in 2020.

$12^{\text {th }}$ WCTR, July 11-15, $2010-$ Lisbon, Portugal
} 
Economic growth is not used directly in the Freight Model Flanders to determine incoming and outgoing flows for the Belgian regions (cf. flow generation in the 4-step model). Instead, the model uses employment per region.

It is possible to examine the relationship between economic growth and employment ${ }^{3}$. Walterskirchen (1999) reports an elasticity of 0.41 for the European Union. Hence, if economic activity increases by $1 \%$, employment may be assumed to rise by $0.41 \%$.

On the basis of available Belgian employment figures and GDP (prices of 2000), it is possible to estimate the following equation:

$\ln ($ employment $)=\alpha+\beta \cdot \ln (G D P)$

The estimated value for $\beta$ is 0.478 , with a t-value of 3.62 and $R^{2}=0.972 .^{4}$ This estimated value may be read as follows: if GDP increases by $1 \%$, employment will rise by $0.478 \%$. This result is also in line with Walterskirchen (1999). A yearly economic growth of $2 \%$ in Belgium may also be expressed in a yearly growth of employment by $0.956 \%$.

On the basis of the above findings, we are able to make the following assumptions for the Belgian regions and apply them in the freight model:

- Low growth: growth employment $-0.239 \%=0.717 \%$

- Normal growth: growth employment $=0.956 \%$

- High growth: growth employment $+0.239 \%=1.195 \%$

\subsubsection{Policy assumptions}

A distinction is made between a "continuation of current policy" and the "implementation of a dynamic policy".

In the assumption of "continuation of current policy", a yearly increase of $0.1 \%$ is assumed in the costs of road and rail transport. An increase in the costs of road transport is considered probable given the advanced deregulation of the road haulage sector. For rail freight, it is assumed that the dominance of national railway companies shall persist. Deregulation will lead to a reduction in national subsidies and will drive prices up (NEA Transport Research and Training \& University of Antwerp, 2007).

These growth percentages should be interpreted as relative figures. In other words, road haulage and rail freight will experience a slightly bigger cost increase than inland navigation.

\footnotetext{
${ }^{3}$ We refer to Okun's Law, giving the relation between the growth of GDP and unemployment, in which the relation between the growth of GDP and employment is a part of it.

${ }^{4}$ Please note that this is a simple time-series estimation, whereby possible time-series effects (e.g. cointegration) are ignored.
} 
In this analysis, it is not necessary to consider the actual growth percentages. Growth percentages that respect the relative position between the modes suffice.

In the assumption of "dynamic policy", we opt for a one-off increase in the vehicle cost of $20 \%$, followed by an annual increase of $0.1 \%$. This is motivated as follows: should the externalities of road transport be fully internalized, then vehicle costs may rise by as much as $60 \%$. This $60 \%$ may be regarded as a maximum impact to be introduced into the model. However, we assume an increase by $20 \%$ because:

- An increase of $60 \%$ is not politically feasible;

- From a modelling point of view, it is not advisable to assume excessive impacts (cf. confidence intervals).

\subsubsection{Assumptions in relation to inland navigation}

In order to simulate cost advantages for inland waterways transport, specific assumptions are introduced.

- Continuation of current policy;

- Additional inland navigation measure: $2 \%$ annual reduction in the cost of inland navigation (e.g. as a result of more efficient use of inland waterways).

\subsubsection{Combination of assumptions}

It is not necessary to consider every possible combination of the foregoing assumptions. Low economic growth combined with a dynamic policy or high economic growth combined with a continuation of current policy are, for example, rather nonsensical. Table 1 provides an overview of the scenarios that are taken into consideration.

Table 1: overview scenarios

\begin{tabular}{|l|l|l|l|}
\hline $\begin{array}{l}\text { Reference } \\
\text { scenario }\end{array}$ & $\begin{array}{l}\text { Economic } \\
\text { assumptions }\end{array}$ & Policy assumptions & Assumptions for inland navigation \\
\hline Scenario 1 & Normal growth & $\begin{array}{l}\text { Continuation of } \\
\text { current policy } \\
\text { current policy }\end{array}$ & Continuation of current policy \\
\hline Scenario 2 & Normal growth & Dynamic policy & Continuation of current policy \\
\hline Scenario 3 & Normal growth & Dynamic policy & $2 \%$ annual cost reduction \\
\hline Scenario 4 & High growth & Dynamic policy & Continuation of current policy \\
\hline Scenario 5 & High growth & Dynamic policy & $2 \%$ annual cost reduction \\
\hline Scenario 6 & Low growth & $\begin{array}{l}\text { Continuation of } \\
\text { current policy }\end{array}$ & Continuation of current policy \\
\hline Scenario 7 & Low growth & $\begin{array}{l}\text { Continuation of } \\
\text { current policy }\end{array}$ & $2 \%$ annual cost reduction \\
\hline
\end{tabular}

Source: own composition. 


\section{DETERMINING FUTURE DEMAND FOR WATERSIDE INDUSTRIAL LAND}

\subsection{General methodology}

To determine the need for additional waterside industrial space, we take as a starting point the predicted tonnage transported by inland navigation in the year 2020. For each district and for each goods category, an indicator has been created expressing the need for land in respectively 2004 and 2020. Some of the growth achieved in that period will be accommodated through already available land. The rest will require newly created space.

The indicator is set on the basis of "regional transfer coefficients". These coefficients represent the tonnage per $\mathrm{m}^{2}$ per year to be transported to and from a given region. To determine these coefficients quantitatively, surveys were carried out (Internet survey and personal interviews).

The survey provides information only about waterside industrial sites (sum of transfer area, storage area and production). The data used were provided by W\&Z and De Scheepvaart. In this manner, we are able to compare between 2004 and 2020 for each of the sites concerned. A positive difference indicates a need for additional space.

\subsection{Quantitative methodology}

The following indicator for the year 2004 can be calculated (per district and per NST-R freight category):

area $_{r i(2004)}=$ tonne $_{r i(2004)} / k_{r i(2004)}^{\prime}$

where:

area $_{r i} \quad=m^{2}$ needed to handle tonne ${ }_{r i}$

tonne $_{r i} \quad=$ tonnage per district $r$ per freight category $i$ (incoming + outgoing flows)

$k_{r i}^{\prime} \quad=$ real relationship between tonne ${ }_{r i}$ and area $a_{r i}$, per freight category $i$, expressed in tonne per $m^{2}$

Crucial in the analysis is the determination of $k_{r i}^{\prime}$. We wish to use an average value for the relationship between tonnage and area. This value can be estimated on the basis of telephone surveys and personal interviews (see 4.3).

In a next step, we calculate an indicator for the year 2020 (based on simulated tonnages generated through the freight model). Suppose that the total surface area used in 2020 is identical to that in 2004, then we can calculate the following indicator:

$k_{r i(2020)}^{\prime}=$ tonne $_{r i(2020)} /$ area $_{r i(2004)}$

$12^{\text {th }}$ WCTR, July 11-15, $2010-$ Lisbon, Portugal 
We can also define the theoretical, optimal relationship between tonnage and area as $k_{r i}$ :

$k_{c i}=$ theoretical, optimal relationship between ton $_{r i}$ and area ${ }_{r i}$ at full capacity, per freight category $i$

If, for example, $k_{r i}^{\prime}$ equals 6 tonnes per $m^{2}$ and $k_{c i}$ equals 11.5 tonnes per $m^{2}$, then there is a surplus of available space; capacity is, in other words, wasted.

If $k_{r i}^{\prime}(2020) \quad>k_{c i}$ then a capacity problem will present itself in 2020 in district $r$ insofar as freight category $i$ is concerned. If $k_{r i(2020)}^{\prime}<k_{c i}$ then no capacity problem will present itself in 2020 in district $r$ insofar as freight category $i$ is concerned.

Future demand for a given area is calculated as:

$$
\text { (ton } \left._{r(2020)} / k_{r i(2020)}^{\prime}\right)- \text { area }_{r i(2004)}
$$

Three values for $k_{r i}^{\prime}(2020)$ may be considered, based respectively on the current regional transfer coefficient $\left(k_{r i(2004)}^{\prime}\right)$, on the economically optimal regional transfer coefficient, and on the maximum regional transfer coefficient (which is not necessarily the economically most efficient one).

If one starts from the current regional transfer coefficient, it is assumed that the company cannot handle more than the present situation. This may be due to the fact that the technology presently applied cannot cope with an increase (e.g. cranes at maximum capacity), or to the fact that the company has reached its production limits. If one starts from values that are higher than the current coefficient, then the underlying assumption is that the handling facilities or the available storage area are not being used to full capacity.

The values of the indicators are estimated on the basis of survey data, as shall be elucidated in the next section.

\subsection{Surveys}

In order to underpin the research with quantitative data, surveys were conducted of companies that are physically located in the proximity of water. Part of the company site is used for the transfer of goods by water.

We opted for two approaches:

- Extensive surveys. Students from the University of Antwerp (Industrial Location Seminar) conducted interviews with a number of companies in waterside locations. In all, 18 companies were contacted, 17 of which were retained for the study.

- Short surveys. On the basis of an Internet survey, a number of key questions were presented to these companies. Databases of the waterways administrators were 
used (Waterwegen en Zeekanaal: 235 companies contacted, 29 of which were retained; De Scheepvaart: 125 companies contacted, 22 of which were retained).

The survey data were used to determine values of the regional transfer coefficient. Alternatively, we might have relied on information from the PPP program ${ }^{5}$ of the Flemish government. Under this program, the Flemish government co-finances infrastructure for inland-waterways-related transfer. For each company participating in this program, information is available regarding incoming and outgoing goods flows by water. Information about company sites is collected by the waterways administration. However, further analysis was not possible, as the administration possesses only partial information regarding the size of these company sites (concessions).

\subsection{Results}

To determine future demand for waterside industrial land, regional transfer coefficients are calculated (section 4.4.1). In a next step, we determine the capacity use of the individual sites (section 4.4.2). Finally, the quantitative results are presented (section 4.4.3).

\subsubsection{Determination of regional transfer coefficients $\left(k^{\prime}\right)$}

Table 2 shows the values of the regional transfer coefficients. We have tried to differentiate maximally between the various freight categories. On the basis of information about total site areas and inland-waterways-related tonnage, the regional transfer coefficient is determined (tonne per $\mathrm{m}^{2}$ per year). Some freight groups, characterized by a low number of observations, were collated. An option was made for median values.

\subsubsection{Determination of capacity}

In section 4.4.1, the regional transfer coefficient per freight category was determined. Next, the question arises to what extent these coefficients may increase (from a technical and economic point of view) before the company needs additional land. In the aforementioned surveys, information was obtained in relation to the capacity use of the company sites (see table 3).

The reported values regarding capacity use were strikingly high. Closer analysis of the results shows that the companies registered capacity use at company level rather than at site level. For example, if an inland vessel arrives three times monthly, the company in question may have reported a capacity utilization of $100 \%$ rather than $15 \%$ (3 vessels / 20 working days).

This may be due to the fact that the company is producing at maximum capacity: the arrival of an additional vessel would, in other words, be useless given the fact that the production

\footnotetext{
${ }^{5}$ Public-private partnership.

$12^{\text {th }}$ WCTR, July 11-15, $2010-$ Lisbon, Portugal
} 
cannot keep up. In order for more freight to be handled, either productivity must be increased (e.g. through technological innovation) or the company site must be expanded (for additional storage or production).

It is hard to determine on the basis of the survey data to what extent capacity is utilized. A further complication is that modal shifts may occur from road transport to inland navigation (i.e. total incoming and outgoing tonnage may be unchanged, but a larger proportion may be transported by inland waterways). Such a situation does not lead to a need for additional land. Therefore, insight is required into what happens with additional flows that were previously not present in the production process.

Table 2. Regional transfer coefficients in tonne per $m^{2}$ per year per freight category (NST-R) for waterside companies

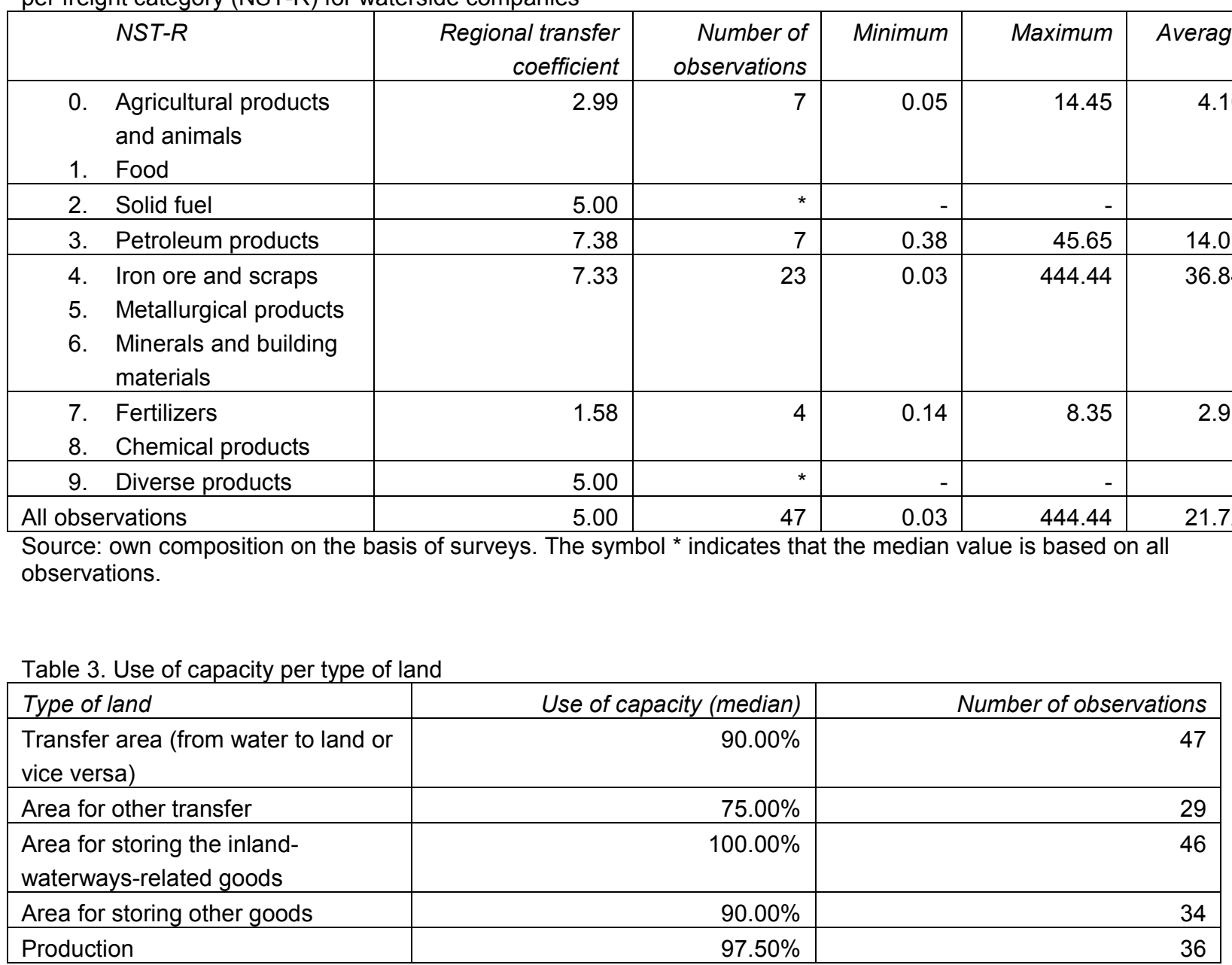

Source: own composition on the basis of surveys.

For the purpose of further calculations, the following values were used:

- $\quad$ the original regional transfer coefficient multiplied by 1.5

- $\quad$ the original regional transfer coefficient multiplied by 2

On the basis of these values, we were able to calculate the crucial turning points in demand for additional land. The values 1.5 and 2 express the potential increase in transfer given the available capacity and technological improvements. They are, however, not purported to be 
real values. They are rather based on expert information and available (foreign) data regarding the relationship between site surface area and transfer. More efficient production or storage could, for example, result in a higher coefficient.

\subsubsection{Quantitative results: future demand}

This paper reports on the results for the reference scenario. The third column of table 4 shows the overall results (in ha) in case of a constant regional transfer coefficient per freight category $\left(k^{\prime}\right.$ constant $\left.=k_{r i(2004)}^{\prime}\right)$. Each increase in tonnage shipped by inland waterways leads to an increase in demand for space. The results shown in the fourth column are based on the assumption that reserve capacity is available, expressed as 1.5 times the original regional transfer coefficient $\left(k^{\prime} \times 1.5=k_{r i(2004)}^{\prime} \times 1.5\right)$. In the fifth column, the regional transfer coefficient has been doubled $\left(k^{\prime} \times 2=k_{r i(2004)}^{\prime} \times 2\right)$.

Table 4 represents the additional demand for land in 2020 on top of existing demand in 2004. It should be noted that this analysis is based on companies physically located in the proximity of water. If demand in 2020 exceeds the available land in 2004, the additional values are included in table 4 . Hence, Table 4 contains the sum of the positive values (= additional land as compared to 2004). On this basis, it is also possible to calculate the theoretical surplus of land.

The results obtained are used first and foremost to prioritize between regions in respect of their need for additional waterside industrial land. In other words, it may be used by government to draw up a list of locations where investment in the availability of land is required. However, we would recommend that government should not rely on the absolute figures provided, but should rather interpret them as a general indicator (great need, moderate need and small need). The figures in Table 4 are calculated on the basis of information obtained from the freight model and the surveys.

On the basis of the aforementioned methodology, we were able too draw up a priority list of NUTS-3 regions (districts) per scenario. The observations were put into 3 groups: great need, moderate need and small need for additional waterside industrial land. The following groups were distinguished in the reference scenario (unchanged policy; see also Figure 1):

- Great need: Antwerpen and Gent;

- Moderate need: Sint-Niklaas, Roeselare, Kortrijk, Brugge, Hasselt and Tielt;

- Small need: Turnhout, Mechelen, Oostende, Halle-Vilvoorde, Aalst, Dendermonde, Oudenaarde, Leuven, Tongeren, Maaseik, Eeklo, Veurne, Diksmuide and leper.

Policy on waterside industrial land may reasonably be assumed to be directed first and foremost at accommodating high-priority regions. It should be noted, in this context, that portrelated needs are taken into account. Hence, the figures for Antwerpen and Gent also reflect the needs of neighboring industrial zones. Therefore, the additional space need not necessarily be located in the port itself. It may also be advisable in other instances to seek additional land in neighboring NUTS-3 regions rather than in the NUTS-3 region under study

$12^{\text {th }}$ WCTR, July 11-15, $2010-$ Lisbon, Portugal 
(given a lack of space in the latter). On the basis of the rankings, it is easier for policymakers to select regions if confronted with financial constraints.

Table 4. Reference scenario (normal growth and no policy change): additional demand in ha in 2020 with a changing regional transfer coefficient

\begin{tabular}{|c|c|c|c|c|}
\hline \multirow[t]{2}{*}{ Groups } & \multirow[t]{2}{*}{ Name of district } & \multicolumn{3}{|c|}{ Additional demand in ha in 2020} \\
\hline & & $k^{\prime}$ constant & $k^{\prime} \times 1.5$ & $k^{\prime} \times 2$ \\
\hline Total & & 3135 & 1063 & 148 \\
\hline \multirow[t]{2}{*}{ Great need } & Antwerpen & 2144 & 756 & 119 \\
\hline & Gent & 603 & 203 & 12 \\
\hline \multirow[t]{6}{*}{ Moderate need } & Sint-Niklaas & 132 & 43 & 7 \\
\hline & Roeselare & 71 & 25 & 3 \\
\hline & Kortrijk & 40 & 9 & 2 \\
\hline & Brugge & 31 & 10 & 1 \\
\hline & Hasselt & 22 & & \\
\hline & Tielt & 18 & 6 & 1 \\
\hline \multirow[t]{13}{*}{ Small need } & Turnhout & 14 & & \\
\hline & Mechelen & 14 & 2 & 0.44 \\
\hline & Oostende & 12 & 4 & 0.99 \\
\hline & Halle-Vilvoorde & 10 & 1 & \\
\hline & Aalst & 9 & 3 & 0.48 \\
\hline & Dendermonde & 5 & 0.47 & \\
\hline & Oudenaarde & 4 & 0.39 & \\
\hline & Leuven & 2 & 0.47 & 0.00 \\
\hline & Tongeren & 2 & & \\
\hline & Maaseik & 1 & 0.03 & \\
\hline & Eeklo & 0.13 & & \\
\hline & Veurne & 0.00 & & \\
\hline & $\begin{array}{l}\text { Diksmuide } \\
\text { leper }\end{array}$ & & & \\
\hline
\end{tabular}

Source: own calculations.

A dynamic policy (single increase of the vehicle cost with $20 \%$, followed by a yearly growth of $0.1 \%$ ) results in a higher demand for inland navigation and thus a higher demand for waterside industrial land. This is also the case if the cost of inland navigation declines. However, we find small differences between the rankings under the different scenarios. This indicates a possible slowness. In other words, it would require quite significant policy changes in order for the various scenarios to impact on the rankings.

Some circumspection is called for in the interpretation of the figures in relation to minor waterways. The calculated figure for the district of Maaseik, for example, is low. However, that is not to say that government should abandon its policy on minor waterways. The method followed in this study is, after all, demand-based: the starting-point is current tonnages. If, in absolute terms, tonnage is small in the base year, this will continue to be so in 2020. Hence, one should taken into account that:

- $\quad$ with respect to small waterways, a supply-driven policy is recommended;

- districts with small waterways may serve as back-up areas for the bigger regions facing spatial constraints. 
Figure 1: Future demand for additional waterside industrial land (great need, moderate need and small need)
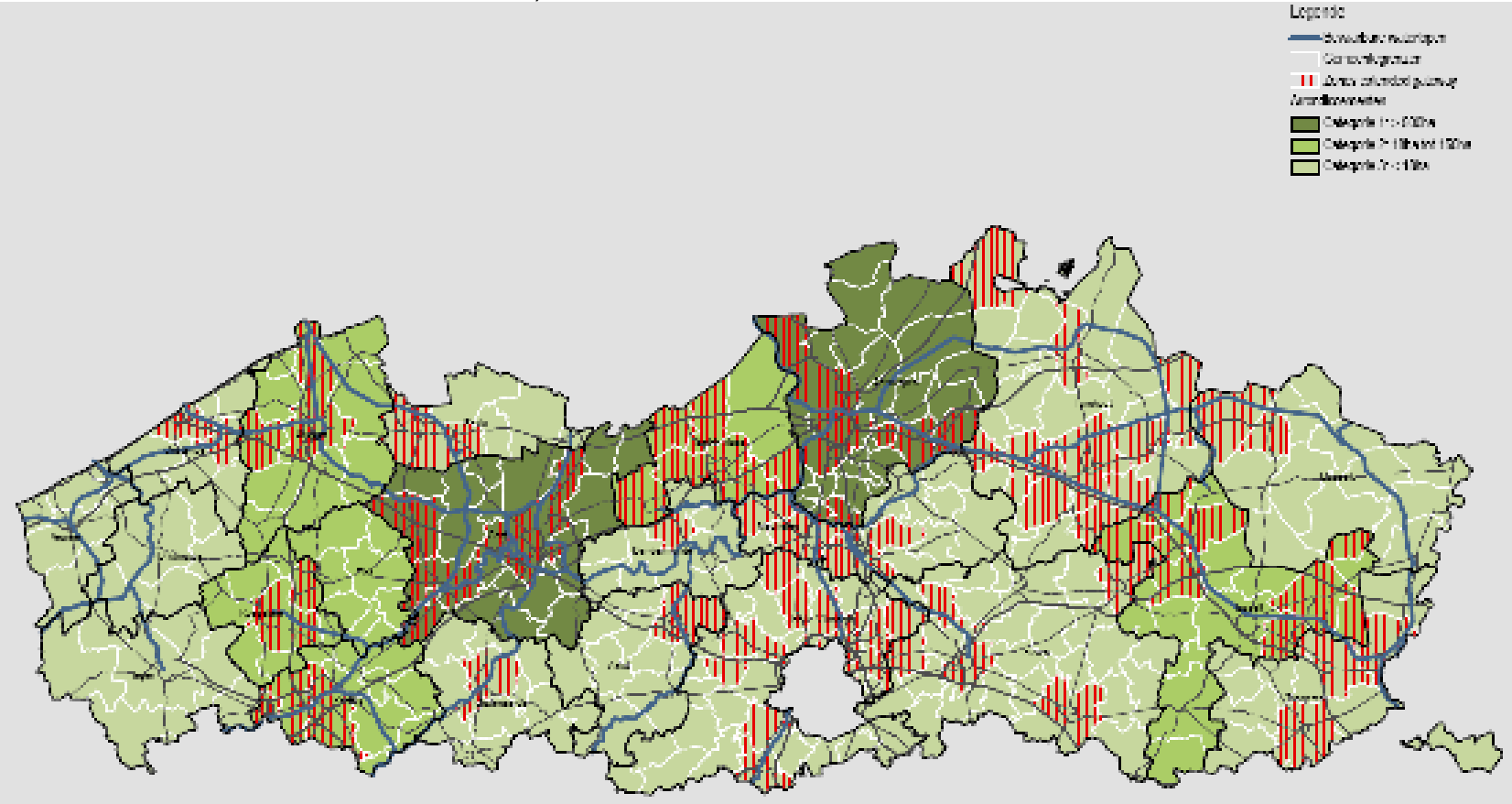

Source: Arcadis and the University of Antwerp; "Categorie 1" = great need, "Categorie 2" = moderate need and "Categorie 3" = small need

\section{CONCLUSIONS}

The findings of the present study can serve as a useful input for scenario-building and a quantitative analysis for the purpose of acquiring better insight into the future needs for waterside industrial land. In this sense, the answers to the research questions posed are valuable to policymakers and operators alike.

It is important for government to assess how demand for waterside land may increase in the future. Some of the growth in inland navigation may be accommodated by existing industrial land, but rest will require additional space. In this context, it is also important that a priority list for investment in such locations should be drawn up.

At the request of the Agency for the Economy (Agentschap Economie) of the Flemish Government, Arcadis and the University of Antwerp (Department of Transport and Regional Economics) are conducting a study into policymaking on the supply of waterside industrial land and transshipment locations. Part of this study consists in a quantitative and qualitative assessment of future industrial and transshipment activities along the navigable waterways of Flanders, taking into account the most likely future scenarios (horizon 2020). The present paper reports on the quantitative assessment, which was performed by the University of Antwerp. 
In this quantitative analysis, the following steps were followed:

- Simulation of inland navigation flows on the basis of scenarios;

- Survey-based determination of regional demand for waterside industrial land;

- Prioritisation of regions for further investment in such land.

The research methodology was demand-oriented. The starting point for the analysis was existing demand and how it may evolve in the future. The horizon was the year 2020, and the analysis was conducted at the Flemish NUTS-3 level (districts).

The simulations of inland navigation flows were based on the Freight Model Flanders (developed by K+P Transport Consultants, Tritel and Mint at the request of "Afdeling Verkeerscentrum" of the Flemish Government).

Eight scenarios were considered: a reference scenario (unchanged policy) and variations on that reference scenario. The scenarios diverge in terms of the three types of basic assumptions made.

- Economic assumptions: normal growth, low growth, high growth;

- Policy assumptions: moderate policy or dynamic policy (road pricing);

- Assumptions for inland navigation: specific cost measures in favor of inland navigation.

To determine the need for land, we started from predictions regarding tonnages transported by inland navigation in the year 2020. For each district and for each goods category, an indicator was created expressing the need for waterside land in respectively 2004 and 2020. Some of the anticipated growth will be accommodated by land already available. The rest will require the use of additional space. The indicator was set by means of "regional transfer coefficients". These coefficients represent the tonnage per $\mathrm{m}^{2}$ per year to be transported to and from a given location.

To quantify these coefficients, surveys were carried out (internet survey and personal interviews). The survey results relate only to sites situated alongside water (sum of transfer area, storage area and production). Data from W\&Z and De Scheepvaart were used. In this manner, it was possible to compare site surface areas in 2004 and 2020. A positive difference indicates a need for additional space.

On the basis of the foregoing methodology, it was possible to draw up a priority list of NUTS3 regions (arrondissementen, or districts) per scenario. The observations were classified into three groups: great need, moderate need and small need for additional waterside industrial land. The following groups were distinguished in the reference scenario (unchanged policy):

- Great need: Antwerpen and Gent;

- Moderate need: Sint-Niklaas, Roeselare, Kortrijk, Brugge, Hasselt and Tielt;

- Small need: Turnhout, Mechelen, Oostende, Halle-Vilvoorde, Aalst, Dendermonde, Oudenaarde, Leuven, Tongeren, Maaseik, Eeklo, Veurne, Diksmuide and leper. 
Policy on waterside industrial sites may reasonably be assumed to be directed first at highpriority regions. It should be noted, in this context, that port-related needs are taken into account. Hence, the figures for Antwerpen and Gent also reflect the needs of neighboring industrial zones. Therefore, the additional space need not necessarily be located in the port itself. It may also be advisable in other cases to seek additional land in neighboring NUTS-3 regions rather than in the NUTS-3 region under study (given a lack of space in the latter). On the basis of the rankings obtained, it is easier for policymakers to select regions for additional investment in landside industrial land under financial constraints.

\section{BIBLIOGRAPHY}

Arcadis and Universiteit Antwerpen (2008a) Aanbodbeleid voor watergebonden bedrijventerreinen en watergebonden overslaglocaties - Werkrapport fase 1. Antwerpen.

Arcadis and Universiteit Antwerpen (2008b) Aanbodbeleid voor watergebonden bedrijventerreinen en watergebonden overslaglocaties - Werkrapport fase 2. Antwerpen.

Borremans, D., Grispen, R., Kienzler, H.-P., Organe, K., Peetermans, E., Van Houwe, P. and D. Zillhardt (2008) Multimodaal goederenmodel brengt goederenstromen in kaart. Het Ingenieursblad (6-7), 14-18.

European Commission (2006) European Energy and Transport - Trends to 2030 - update 2005. Brussel.

Federaal Planbureau (2008) Economische vooruitzichten 2008-2013 - Communiqué. Brussel.

Nea Transport Research and Training \& Universiteit Antwerpen (2007) Vervoersprognoses IJzeren Rijn. Rijswijk.

Walterskirchen (1999) The relationship between growth, employment and unemployment in the EU, paper presented at workshop European economists for an alternative economic policy (TSER network). 